\title{
ANALISIS DAN PERANCANGAN SMART DUMP MENGGUNAKAN ARDUINO MEGA 2560 Rev3 DAN GSM SIM900
}

\author{
Johanes Ohoiwutun \\ Jurusan Teknik Elektro \\ POLITEKNIK KATOLIK SAINT PAUL SORONG \\ johnohoiwutun@gmail.com
}

\begin{abstract}
ABSTRAK
Perkembangan ilmu pengetahuan dan teknologi (IPTEK) dewasa ini sangat pesat dan mempengaruhi kehidupan masyarakat untuk melangkah lebih maju (moderenisasi), berpikiran praktis dan sederhana. Untuk mewujudkan ide ini ada beberapa hal yang harus dikerjakan terlebih dahulu antara lain, studi literatur, setelah itu dapat memulai dengan perancangan model alat, agar kita dapat tahu dimana letak setiap komponen atau sensor di letakkan. Setelah itu kita dapat menyiapkan alat dan bahan yang akan digunakan "Tempat Sampah Otomatis" ini menggunakan Arduino mega 2560 Rev3 sebagai pengontrol, Sensor PING HC-SR04 sebagai pendeteksi kedatangan objek dan juga pendeteksi kapasitas tempat sampah, LCD sebagai alat untuk menampilkan kapasitas tempat sampah dan ucapan terima kasih, Module ISD 1820 akan menyampaikan kapasitas tempat sampah apabila telah penuh, Motor DC sebagai alat penggerak untuk membuka dan menutup tutup tempat sampah, Limit Switch sepagai pemutus dan penyambung siknyal saat tutup tempat sampah akan membuka ataupun akan menutup, Module GSM SIM900 sebagai pengirim pesan singkat apabila tempat sampah telah penuh, Power Supply sebagai pemberi daya.
\end{abstract}

\section{KATA KUNCI :}

Tempat Sampah Otomatis, mikro control, module GSM SIM900, module ISD1820, LCD, PING HCSR04, motor DC, power supply, limit switch. 
BAB I

\section{PENDAHULUAN}

\subsection{Latar Belakang}

Perkembangan ilmu pengetahuan dan teknologi (IPTEK) dewasa ini sangat pesat dan mempengaruhi kehidupan masyarakat untuk melangkah lebih maju (moderenisasi), berpikir praktis dan simple.

Contoh untuk membuka dan menutup tempat sampah harus dilakukan

menggunakan tangan ataupun menggunakan kaki, untuk itu dirancanglah sebuah alat agar kerja tempat sampah tersebut lebih efisien, yaitu perancangan tempat sampah otomatis.

\subsection{Rumusan Masalah}

Dari latar belakang yang disampaikan rumusan masalah yang diperoleh adalah :

1) Bagaimana membuat Tempat Sampah Otomatis dengan menggunakan 4 (empat) buah Sensor HC SR-04 untuk mendeteksi kedatangan objek.?

2) Bagaimana peralatan Tempat Sampah Otomatis ini dapat dikontrol menggunakan Arduino MEGA $2560 \operatorname{Rev} 3$ ?

\subsection{Tujuan dan Manfaat Pembuatan}

\subsubsection{Tujuan}

Tujuan dari pembuatan alat ini adalah untuk menambah wawasan dalam teknologi mikrokontrol dan mempermudah manusia dalam membuang sampah.

\subsubsection{Manfaat}

Manfaat dari pembuatan tempat sampah otomatis ini adalah mempermudah manusia dalam hal membuang sampah, yang mana sipembuang sampah tidak perlu lagi menyentuh tutup tempat sampah yang penuh dangan bakteri dan berbahaya bagi kesehatan.

\section{BAB II}

\section{TINJAUAN PUSTAKA}

\subsection{Pengertian Sampah}

Definisi sampah menurut UU18/2008 tentang Pengelolaan Sampah [68] adalah sisa kegiatan sehari-hari manusia dan/atau proses alam yang berbentuk padat.

\subsection{Modul GSM SIM900}

Modul GSM SIM900 adalah peralatan yang didesain supaya dapat digunakan untuk aplikasi komunikasi dari mesin ke mesin atau dari manusia ke mesin.

Dengan adanya sebuah modul GSM SIM900 maka aplikasi yang dirancang dapat dimonitoring dari jarak jauh dengan menggunakan jaringan GSM SIM900 sebagai media akses. Modul GSM SIM900 dapat dilihat pada Gambar. 2.1 


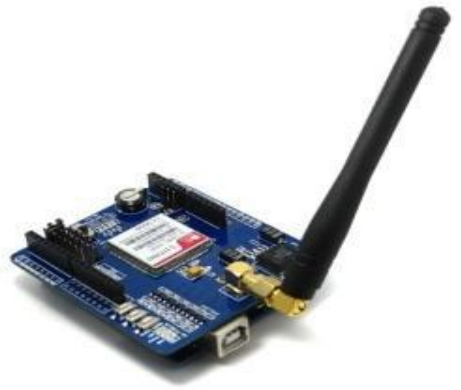

Gambar 2.1 Bentuk Fisik Modul GSM SIM900

\subsection{Mikrokontrol Arduino MEGA 2560}

\section{$\operatorname{Rev3}$}

mikrokontroler adalah sebuah

sistem komputer fungsional dalam sebuah chip. Di dalamnya terkandung sebuah inti processor, memori (sejumlah kecil RAM, memori program, atau keduanya), dan perlengkapan input output. Dengan kata lain, mikrokontroler adalah suatu

alat elektronika digital yang mempunyai masukan dan keluaran serta kendali dengan program yang bisa ditulis dan dihapus dengan cara khusus, Beberapa karakteristik dan fitur yang dimiliki oleh Arduino MEGA2560 Rev3 diantaranya dapat dilihat pada Gambar

\footnotetext{
Microcontroller ATmega2560 Rev3

$>$ Operating Voltage $5 \mathrm{~V}$

Input Voltage (recommended) 7 $12 \mathrm{~V}$

Input Voltage (limits) 6-20V

Digital I/O Pins 54 (of which 14 provide PWM output)

Analog Input Pins 16

DC Current per I/O Pin $40 \mathrm{~mA}$

DC Current for $3.3 \mathrm{~V}$ Pin $50 \mathrm{~mA}$
}

Flash Memory 256 KB of which 8 $K B$ used by bootloader

SRAM $8 \mathrm{~KB}$

EEPROM $4 \mathrm{~KB}$

Clock Speed $16 \mathrm{MHz}$

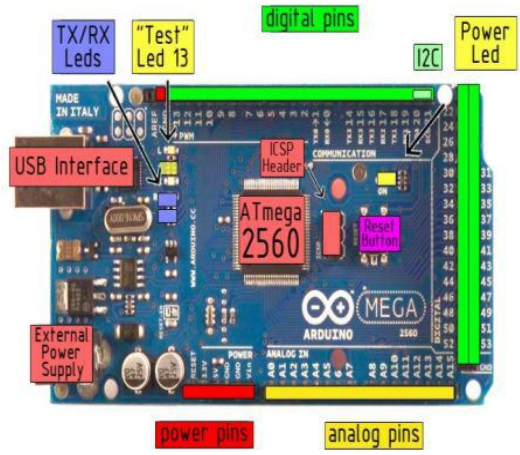

Sumber :

ecadio.com/belajar-dan-

mengenal-arduino-mega

Gambar 2.2 Arduino

MEGA2560 Rev3

\subsection{PING (HC-SR04)}

Sensor ultrasonic disebut sebagai sensor ultrasonik karena sensor ini menggunakan gelombang ultrasonik (bunyi ultrasonik),

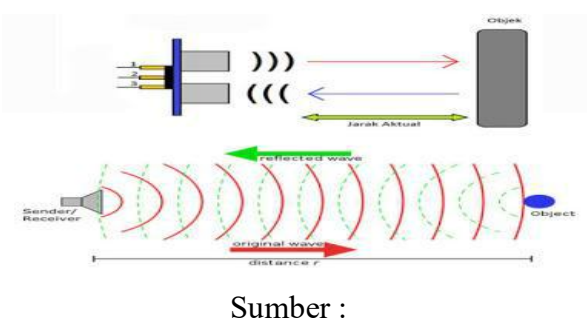

www.elangsakti.com/2015/05/sensorultrasonik.html

Gambar 2.3 Cara Kerja Sensor Ultrasonic

Sensor HC SR-04 merupakan salah satu sensor yang digunakan untuk mendeteksi jarak. Berbeda dengan 
sensor jarak yang menggunakan inframerah,

bentuk fisik sensor PING HC SR-04 dapat dilihat pada Gambar. 2.4

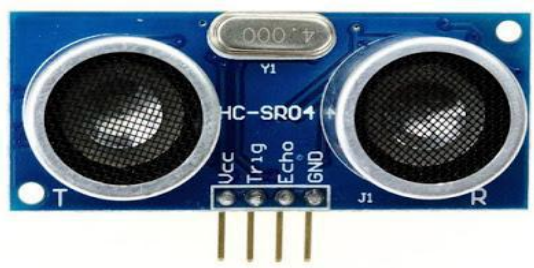

Sumber :

http://www.elangsakti.com/2015/05/sensorultrasonik.html

Gambar 2.4 Bentuk Fisik sensor PING HC

$$
\text { SR-04 }
$$

\subsection{LCD (Liquid Crystal Display) $16 \times 2$}

Liquid Cristal Display (LCD) adalah salah satu komponen elektronika yang berfungsi sebagai tampilan suatu data, baik karakter, huruf ataupun grafik

Bentuk Fisik $L C D$ dapat dilihat pada Gambar. 2.5

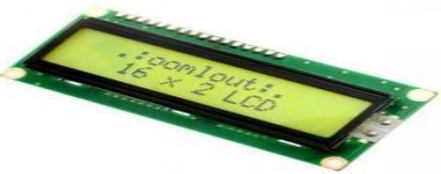

Sumber :

ramdhani.blog.pcr.ac.id/2017/04/19/pertemu an-12-modul-11-lcd/

Gambar 2.5 Bentuk Fisik $L C D$

\section{Module ISD 1820 (Voice Recorder)}

Module ISD1820 adalah sebuah module chip tunggal yang berfungsi sebagai perekam suara dengan kapasitas penyimpanan memori $3,2 \mathrm{~K}$ mampu merekam maksimal 20 detik dengan outputan langsung pada speaker $8 \quad$ OHM (rekomendasi datasheet) atau speaker aktif, dan tegangan kerja hanya $3,3 \mathrm{~V}$.

Berikut ini tampilan atas dan fungsi masing masing tombol. Module ISD 1820 dapat dilihat pada Gambar. 2.11

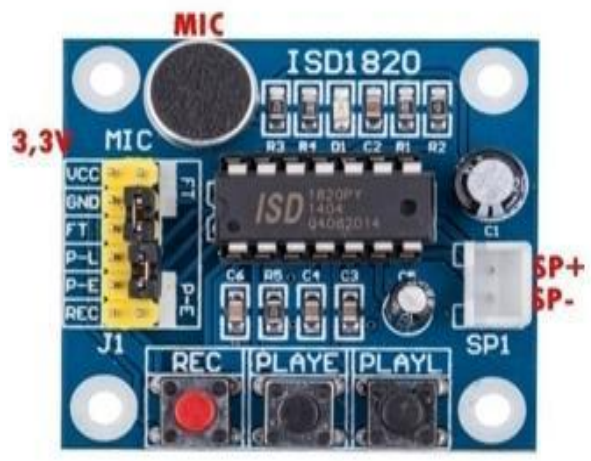

Sumber : www.sfe-

electronics.com/blog/news/tutorialmodule-perekam-suara-sound-recorderisd1820 Gambar 2.11 Module ISD 1820

\section{BAB III}

\section{METODOLOGI PENELITIAN DAN PERANCANGAN SISTEM}

\subsection{Metode Penelitian dan Perancangan}

\subsubsection{Studi Literatur}

Studi literatur digunakan untuk memperoleh informasi, dasar teori yang diperoleh dari buku dan internet sebagai studi pustaka yang mendukung pembuatanTempat Sampah Otomatis Menggunakan Arduino MEGA2560 Rev3 dan GSM SIM 900 


\subsubsection{Perancangan Model Alat}

Pada proses perancangan dan pembuatan Tempat Sampah Otomatis Menggunakan

Arduino MEGA2560 Rev3 dan GSM SIM900 ini, menggunakan Sketch Up 2016, untuk menggambar desain atau model alat yang tampak seperti gambar. Model Perancangan Alat dapat dilihat Pada Gambar. 3.1 sampai Gambar. 3.6

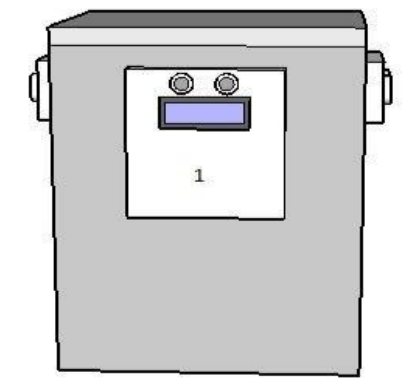

Gambar 3.1 Model Perancangan Alat Tampak Depan

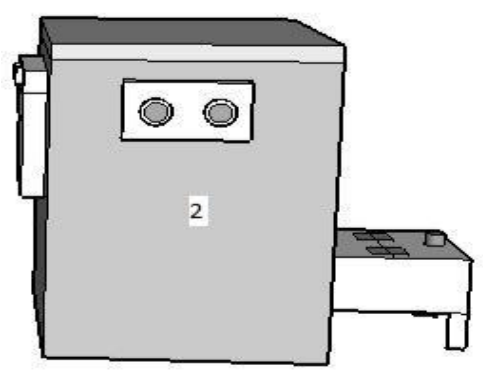

Gambar 3.2 Model Perancangan Alat Tampak Samping Kiri

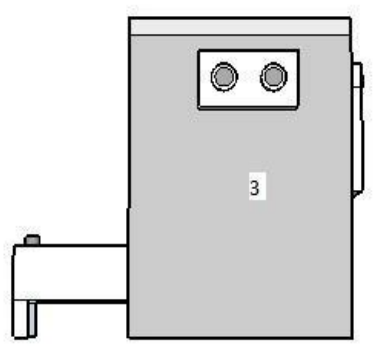

Gambar 3.3 Model Perancangan Alat Tampak Samping Kanan

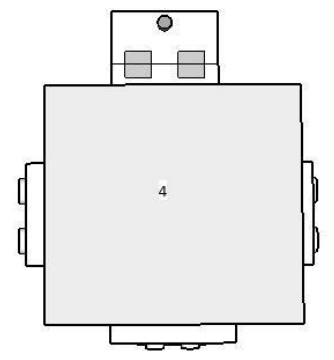

Gambar 3.4 Model Perancangan Alat Tampak Atas

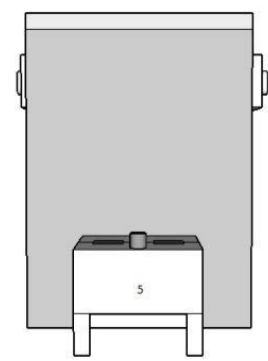

Gambar 3.5 Model Perancangan Alat Tampak Belakang

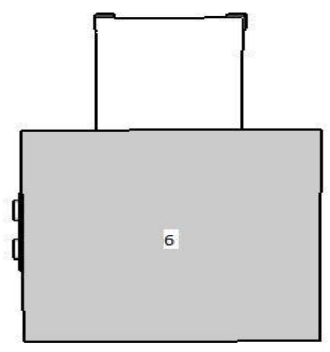

Gambar 3.6 Model Perancangan Alat Tampak Bawah 


\subsection{Prinsip Kerja Alat}

Rancang Bangun Tempat Sampah

Otomatis Menggunakan Arduino

MEGA2560 Rev3 dan GSM SIM900

bekerja dengan cara :

1) Tempat sampah otomatis ini menerima tegangan dari power supply

2) Yang mana saat saklar power supply diaktifkan tegangan akan tersalurkan ke :

a) Arduino MEGA2560 Rev3

b) IC 7805 (1)

c) IC 7805 (2)

d) Penurun tegangan (Converter $D C$ to $D C$ )

e) Modul GSM SIM900

3) Dari Arduino MEGA2560 Rev3 akan menyalurkan tegangan ke :

a) Limit Switch buka

b) Limit switch tutup

c) Modul ISD 1820 (Voice Recorder)

Dari IC7805 (1) akan menyalurkan tegangan ke :

a) Liquid Crystal Display (LCD)

Dari IC7805 (2) akan menyalurkan tegangan ke :

a) Sensor Ultrasonic (PING HCSR04) 1,2,3 dan 4

Dari penurun tegangan (Converter $D C$ to $D C$ ) akan menyalurkan tegangan ke :

a) Driver motor $D C$

4) Saat semua komponen telah mendapat tegangan maka sensor PING HC-SR04 (4) akan bekerja mengirim sinyal ke Arduino
$M E G A 2560 \operatorname{Rev} 3$ dan akan diproses oleh Arduino MEGA2560 Rev3,

a) Jika tempat sampah kosong ( $\geq$ $10 \mathrm{~cm})$ maka :

Sensor PING HC-SR04 $(1,2,3$,$) akan bekerja mendeteksi$ objek dan tampilan $L C D$ akan menampilkan

"TEMPAT SAMPAH MASIH KOSONG”.

b) Jika tempat sampah penuh $(\leq 10 \mathrm{~cm})$ maka :

Sensor PING HC-SR04 (1,2,3,) tidak akan bekerja dan tampilan $L C D$ akan menampilkan "TEMPAT SAMPAH SUDAH PENUH" dan Arduino MEGA2560 Rev3 akan mengirimkan sinyal keModul GSM SIM900 dan Modul ISD 1820 (Voice Recorder) untuk pemberi tahuan melalui Speaker dan SMS kepada operator.

Bila sensor PING HCSR04 (1,2,3,) mendeteksi objek $(\leq \quad 10 \mathrm{~cm})$ maka :

Sensor PING HC-SR04 (1,2,3,) akan mengrim sinyalke Arduino MEGA2560 Rev3 dan akan diproses oleh Arduino MEGA2560 Rev3 dan Arduino $M E G A 2560 \quad \operatorname{Rev} 3$ akan mengirimkan sinyal ke Driver motor $D C$ dan Driver motor $D C$ akan mengaktifkan motor buka, sementara itu tampilan $L C D$ akan menampilkan "TERIMA KASIH SAMPAH SUDAH DIBUANG", dan saat penutup 
tempat sampah menyentuh Limit

Switch buka, Limit Switch buka

akan mengirim sinyal ke

Arduino MEGA2560 Rev3 dan

Arduino MEGA2560 Rev3 akan

memproses sinyal tersebut dan

mengirim sinyal kepada Driver

motor $D C$ dan Driver motor $D C$

akan menghentikan motor $D C$

dan pada saat objek meninggalkan tempat sampah $(\geq$ $10 \mathrm{~cm}$ ) sensor PING HC-SR04 $(1,2,3$, ) akan memberi sinyal kepada Arduino MEGA2560 Rev3 dan akan diproses oleh

Arduino MEGA2560 Rev3 lalu Arduino MEGA2560 Rev3 akan mengirim sinyal ke Driver motor $D C$ lalu Driver motor $D C$ akan mengaktifkan motor tutup, dan saat penutup tempat sampah mulai menutup sensor PING HC-SR04 (4) tetap akan bekerja dan apabila dalam proses

menutup penutup tempat sampah sensor PING HC-SR04

(4) $(\leq 10 \mathrm{~cm})$ maka sensor PING HC-SRO4 (4) akan mengirim sinyal ke Arduino MEGA2560 Rev3 lalu Arduino

MEGA2560 Rev3 akan mengirim sinyal ke Driver motor $D C$ lalu Driver motor $D C$ akan mengaktifkan motor untuk berhenti dan tampilan $L C D$ akan menampilkan

"TEMPAT SAMPAH SUDAH PENUH" dan Arduino MEGA2560 Rev3 akan mengirimkan sinyal ke GSM SIM900 dan Modul ISD 1820 (Voice Recorder) untuk pemberi tahuan melalui Speaker dan SMS kepada operator, dan apa bila sensor PING HC-SRO4 (4) tetap membaca $(\geq 10 \mathrm{~cm})$ maka proses menutup penutup tempat sampah terus berlanjut sampai penutup tempat sampah menyentuh Limit switch tutup maka Limit switch tutup akan mengirim sinyal ke Arduino MEGA2560 Rev3 lalu Arduino $M E G A 2560$ Rev3 akan mengirim sinyal ke Driver motor $D C$ lalu Driver motor $D C$ akan menghentikan motor dan pada saat itu $L C D$ akan menampilkan "TEMPAT SAMPAH MASIH KOSONG”.

BAB IV

PENGUJIAN ALAT DAN

PEMBAHASAN

\subsection{Hasil Perancangan}

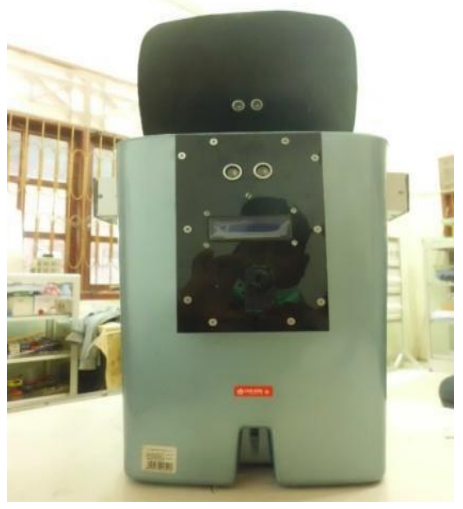

Gambar 4.1 Tampak Depan 


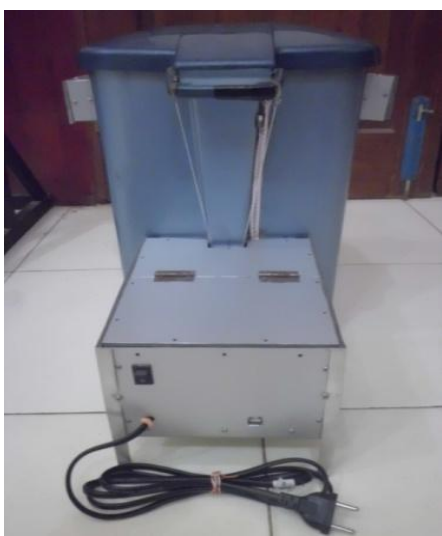

Gambar 4.2 Tampak Belakang

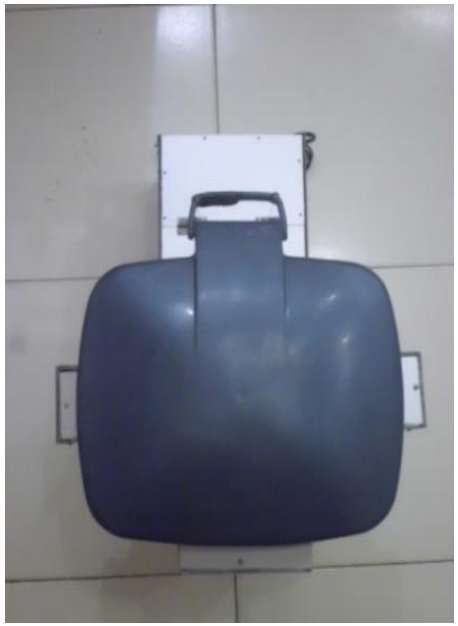

Gambar 4.3 Tampak Atas

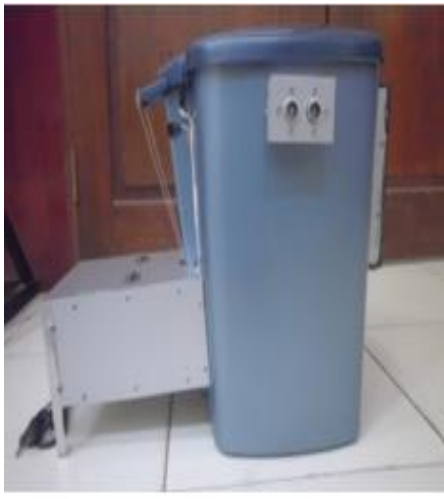

Gambar 4.4 Tamplak Samping
4.2 Pengujian Program $I D E$ pada Arduino MEGA2560 Rev3

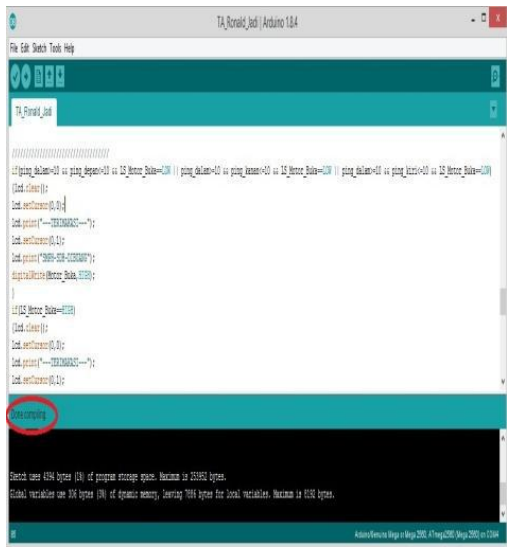

Gambar 4.5 Tampilan Sketch Arduino Saat Program Valid

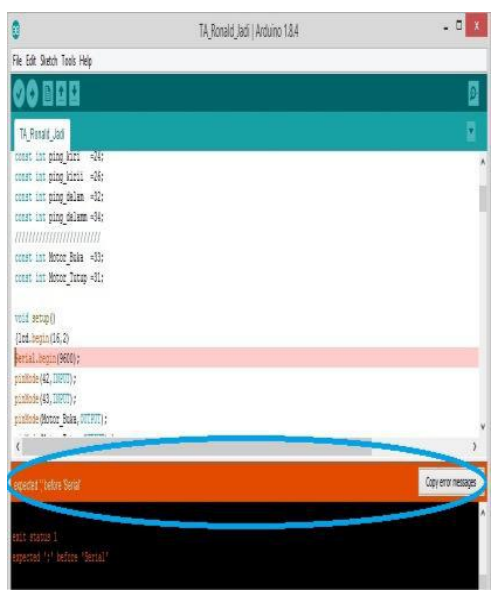

Gambar 4.6 Tampilan Sketch Arduino Saat Program Invalid

4.3 Pengujian Rangkaian Power Supply

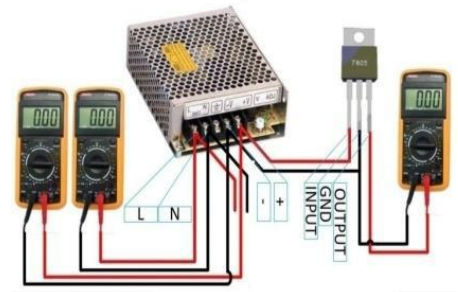

Gambar 4.7 Rangkaian Power Supply $10 \mathrm{VDC}$ dan IC7805 5VDC 


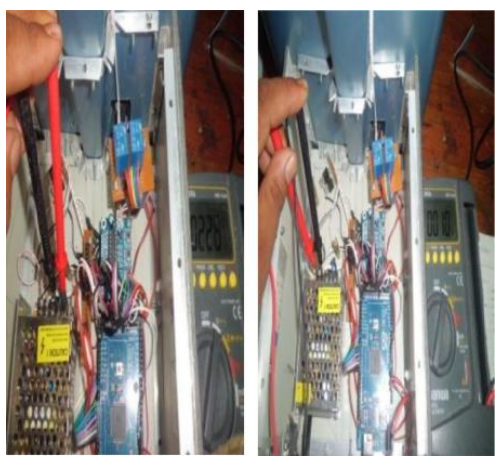

Gambar 4.8 Pengujian Input Output Pada Power Supply

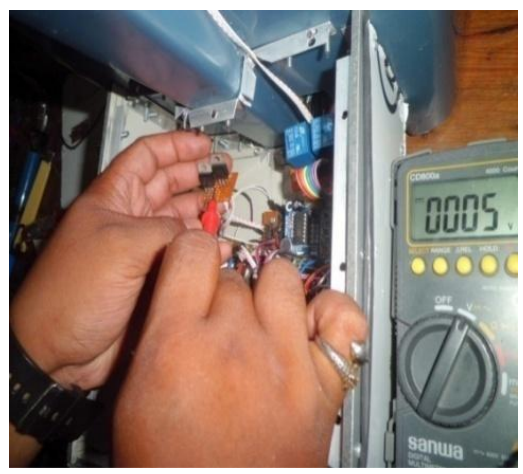

Gambar 4.9 Pengujian Output IC7805

\subsection{Pengujian Port Pada Arduino} $M E G A 2560 \operatorname{Rev} 3$

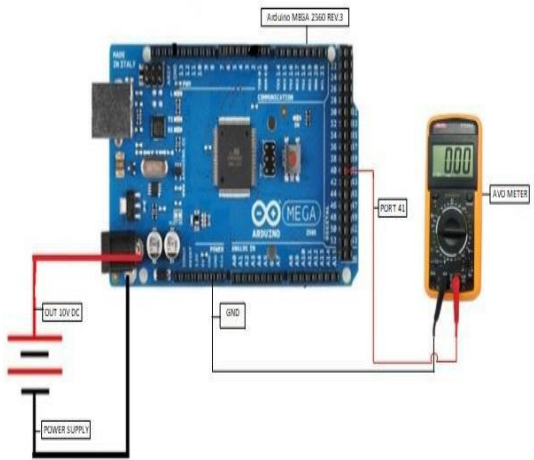

Gambar 4.10 Rangkaian Pangujian Port Digital

Pengujian Port I/O Arduino MEGA2560 Rev3 dilakukan dengan cara mengukur tegangan keluaran pada portnya.

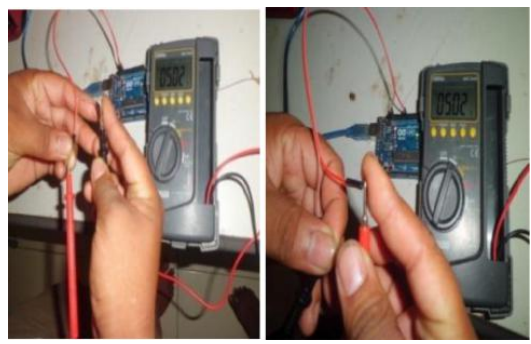

Gambar 4.11 Hasil Pengukuran

Tegangan Pada Port 7 dan Port 13

\subsection{Pengujian Tampilan $L C D$}

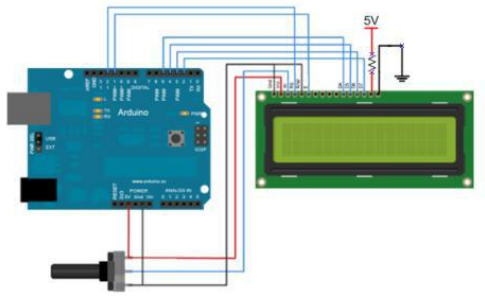

Gambar 4.12 Rangkaian LCD

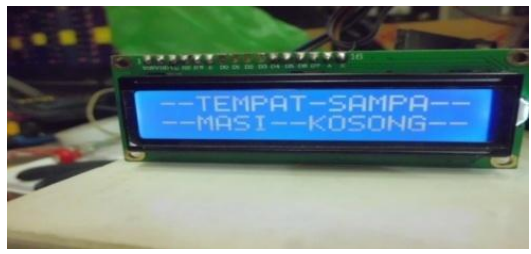

Gambar 4.13 Tempat Sampah Kosong

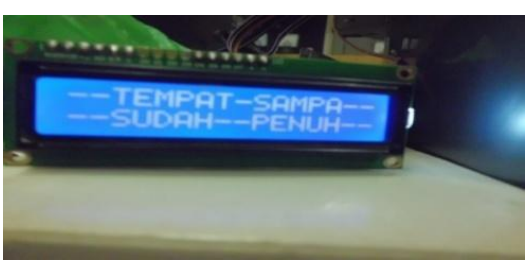

Gambar 4.14 Tempat Sampah Penuh

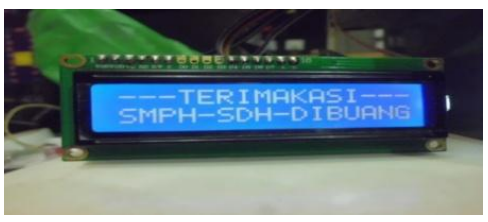

Gambar 4.15 Tampilan Terima Kasih 


\section{BAB V \\ PENUTUP}

\subsection{Kesimpulan}

Adapun kesimpulan yang dapat diambil dari hasil pengujian "Tempat Sampah Otomatis Berbasis Arduino MEGA2560 Rev3 dan GSM SIM900" adalah sebagai berikut:

1) Jika tempat sampah tidak penuh, tutup tempat sampah akan terbuka apabila ada objek yang mendekati sensor PING HC SR-4 $(1,2,3)$ dari sisi kiri, kanan, dan depan, $\leq 10 \mathrm{~cm}$ dari tempat sampah.

2) Apabila sensor PING HC SR-4 (4) yang mendeteksi kapasitas tempat sampah mendeteksi bahwa jarak sampah $\leq 10 \mathrm{~cm}$, maka motor penggerak tidak akan bekerja dan juga sensor PING HC SR-4 $(1,2,3)$ bila mendeteksi objek akan menampilkan

"TEMPAT

SAMPAH SUDAH PENUH" pada tampilan $L C D$ dan pemberitahuan melalui Speaker.

3) Status tempat sampah akan ditampilkan pada layar $L C D$.

4) Apabila sampah sudah melewati ( $\leq$ $10 \mathrm{~cm})$ maka GSM SIM900 akan mengirimkan informasi kepada

petugas kebersihan melalui SMS

\subsection{Saran}

Adapun saran yang dapat diambil dari hasil pengujian "Tempat Sampah

Otomatis Berbasis Arduino MEGA2560 Rev3 dan GSM SIM900 adalah sebgai berikut :

1) Apabila menggunakan sensor $P I N G$ $H C \quad S R-4$ sebagai pendeteksi kedatangan objek batasilah dalam jarak yang tidak terlampau jauh agar sensor PING HC SR-4 tidak mendeteksi objek yang hanya lewat.

2) Penggunaan PING HC SR-4 sebagai pendeteksi jarak kedatangan objek membutuhkan kalibrasi pada program sebelum digunakan, agar jarak hitung $P I N G$ $H C S R-4$ sesuai dengan batas yang ditentukan.

3) Agar menggunakan Resistor yang tapat pada rangkaian $L C D$ untuk memudahkan pembacaan.

4) Tempat Sampah Otomatis ini dapat dikembangkan untuk mendeteksi objek atau wajah manusia. 


\section{DAFTAR PUSTAKA}

[1] Chandra, F, D., \& Arifianto. (2011). Jago Elektronika, Rangkaian sistem otomatis. Jakarta : Kawan Pustaka.

[2] Dian Artanto, 2012.Interaksi Arduino dan LabVIEW.Jakarta : PT Alex Media Komputindo.

[3] Djuandi, Feri. 2011."Pengenalan Arduino". Jakarta: Penerbit Elexmedia.

[4] Guide Module. 2014, IcomSat v 1.1-SIM900 GSM/GPRS Shield.

[5] Hartono, Jogianto MBA,Ph.D. Konsep Dasar Pemrograman Bahasa C. ANDI Yogyakarta.Yoyakarta, 1993

[6] Kadir, Abdul. 2013. Panduan Praktis Mempelajari Aplikasi Mikrokontroler dan Pemogramannya Menggunakan Arduino.Yogyakarta : C.V Andi Offset

[7] Kadir, A. 2015. "Buku Pintar Pemograman” Yogyakarta : Mediakom

[8] Malvino Albert P. (1994) Prinsip-Prinsip Dasar Elektronika. Buku satu, Salemba Teknika (diterjemahkan oleh Ir. Alb. Joko Santoso, MT.)

[9] Setiawan Iwan, S.T., M.T. 2009 Buku Ajar Sensor dan Transducer.Semarang 